\title{
Mariner Mars 1969: Atmospheric Results
}

\author{
Conway B. Leovy \\ University of Washington, Seattle 98105 \\ BradFord A. SMith \\ New Mexico State University, Las Cruces 88001 \\ ANDREw T. Young \\ Jet Propulsion Laboratory, Pasadena, California 91103 \\ ROBERT B. LEIGHTON \\ California Institute of Technology, Pasadena 91109
}

\begin{abstract}
Results of investigation of probable atmospheric effects appearing in Mariner '69 TV pictures that have undergone noise removal and preliminary decalibration are described. Two distinct types of haze are distinguished: north polar haze, seen prominently against the face of the planet in blue photographs, and thin haze, usually identified by its appearance on the limb and not strongly colored. Thin haze is surprisingly widespread, particularly in the southern hemisphere. Discrete bright features, which may be evidence for condensation on the ground or in the atmosphere, are described. These occur where bright features have of ten been seen from earth, in a region where very large multiple-ringed structures seem to dominate the surface morphology. The speculation that these may be evidence for local water-vapor exchange between ground and atmosphere is raised, and some constraints on local subsurface water-vapor sources in the Mars tropics are described. Finally, some implications of the Mariner '69 results for atmospheric exploration by Mariner '71 are briefly discussed.
\end{abstract}

Early inspection of unprocessed Mars Mariner ' 69 pictures led to several preliminary conclusions concerning the state of the atmosphere during the Mariner 6 (M6) and Mariner 7 (M7) encounters [Leighton et al., 1969]. Briefly, these results can be summarized as follows: (1) surface features were not noticeably obscured by a prevailing blue haze, (2) optically thin haze layers were seen above the limb in several places, and (3) the atmosphere was remarkably free of discrete dense clouds, although a very few areas showed marked afternoon brightening. These brightenings did not appear to be caused by convective clouds, but several occur in a region having a peculiar and perhaps a unique surface morphology, in which multiple-ringed structures several hundred kilometers in diameter are prevalent.

Contribution 225, Department of Atmospheric Sciences, University of Washington.

Copyright (C) 1971 by the American Geophysical Unıon.
The purpose of this paper is to refine and to extend these conclusions, on the basis of a further examination and analysis of more completely processed pictures, particularly those that have been filtered and enhanced to improve discriminability of small-scale features. Other pictures used have had geometrical corrections and firstorder photometric decalibration applied. Complete photometric decalibration is an iterative process involving application of a variety of consistency checks. This process is still incomplete and, for this reason, only limited results based on photometrically decalibrated data are presented here. For example, analysis of light levels near the terminator might provide useful information on atmospheric scattering, but this analysis has not yet been attempted. Details of the picture-data processing may be found elsewhere [Rindfleisch et al., 1971]. Photometric characteristics of the two high-resolution cameras (B cameras) are discussed by Young and Collins [1971]. Near-encounter frames processed for 
maximum discriminability of small scale features are given in the paper by Dunne et al. [1971].

The principal new results of this investigation concern the distribution and characteristics of the two distinct types of hazes that are identified. We distinguish these tentatively as north polar haze, which is seen as a brightening on the face of the planet, particularly in blue photographs, and thin haze, which is usually identified on the limb and is not strongly colored. Thin haze is very widespread: it is prevalent in the southern hemisphere between latitudes $-20^{\circ}$ and $-50^{\circ}$ but is not limited to this belt. Although the observed thin haze does not obscure the surface, it is dense enough in some cases to cause limb brightening and may have a subtle influence on the contrast of surface features. The nature of the particles responsible for thin haze is not known, but, in one instance at least, it appears that it is not due to particles of frozen carbon dioxide.

In the next section, we discuss the planet-wide distribution of all features in the Mariner ' 69 pictures that we believe to be in the atmosphere or directely related to atmospheric processes. Section 2 deals with the observed characteristics of the thin hazes and discusses some possible implications of these observations. Section 3 discusses discrete bright patches and their implications. Implications of these results for exploration of Mars by Mariner '71 are discussed in the last section.

\section{Distribution of Atmospheric Phenomena}

Figure 1 and Table 1 indicate the Mars coordinate locations (west longitude system), type of phenomenon, pictures in which best seen, method of identification, and height above the surface, for inferred atmospheric phenomena.

The regions delineated comprise a conservative estimate of the extent of the atmospheric phenomena. Thin hazes are identified by limb effects only if a distinct detached layer can be seen, or if geometrically corrected pictures reveal a limb projection either contiguous with a detached layer or contiguous with a region appearing on the face of the planet that shows marked brightening as it rotates toward the limb. The extreme western limit of the identified thin hazes seen in the southern hemisphere in Mariner 6 and 7 farencounter frames is determined by the passage of the limb out of the camera field during the spacecraft approach to the planet in late far encounter. The eastern limit is governed by the picture resolution: the poorest resolution for which layers at the indicated heights $(15-35 \mathrm{~km})$ would be detectable is about $11 \mathrm{~km}$ per pixel. Thus the thin hazes, $K, L$, and $M$, seen on the

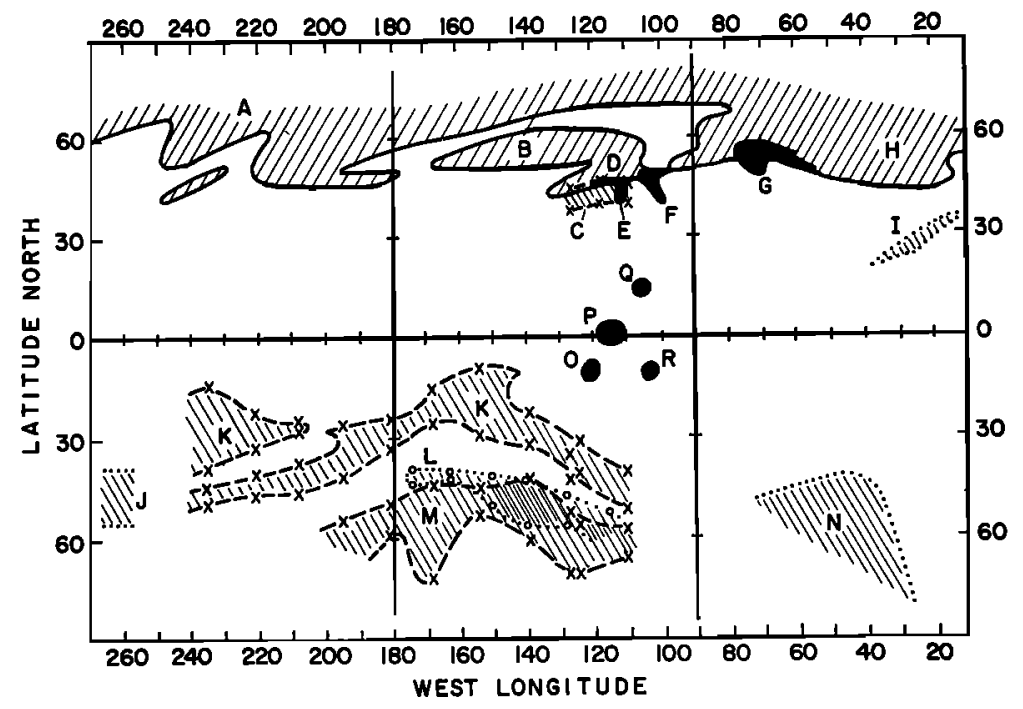

Fig. 1. Mars coordinate of observed or inferred atmospheric phenomena. Identification letters correspond to those in Table 1. (x) indicates limit of thin haze seen on the limb in far-encounter M6 frames; (o) indicates corresponding haze limits for M7. 
TABLE 1. Possible Atmospheric Phenomena in Mariner 6 and 7 Pictures

\begin{tabular}{|c|c|c|c|c|}
\hline $\begin{array}{l}\text { Atmospheric } \\
\text { Phenomena }\end{array}$ & Type & $\begin{array}{l}\text { Method of } \\
\text { Identification }\end{array}$ & $\begin{array}{c}\text { Best } \\
\text { Pictures }^{2}\end{array}$ & $\begin{array}{l}\text { Height, } \\
\text { km }\end{array}$ \\
\hline A & $\begin{array}{l}\text { North polar } \\
\text { haze }\end{array}$ & $\begin{array}{l}\text { Bright area in far } \\
\text { encounter }\end{array}$ & $\begin{array}{c}\text { 6F41, } \\
7 \mathrm{~F} 55-7 \mathrm{~F} 60\end{array}$ & $\cdots$ \\
\hline B & $\begin{array}{l}\text { North polar } \\
\text { haze }\end{array}$ & $\begin{array}{l}\text { Bright area in far } \\
\text { encounter }\end{array}$ & $\begin{array}{l}\text { 6F34-6F38, } \\
7 \text { F70-7F75 }\end{array}$ & $\cdots$ \\
\hline $\mathrm{C}$ & Thin haze & $\begin{array}{l}\text { Detached limb layer } \\
\text { in M6 far encounter }\end{array}$ & $6 \mathrm{~F} 40,6 \mathrm{~F} 41$ & 50 \\
\hline $\mathrm{D}$ & $\begin{array}{l}\text { North polar } \\
\text { haze }\end{array}$ & $\begin{array}{l}\text { Bright area in far } \\
\text { encounter }\end{array}$ & 6F34, 7F74 & $\cdots$ \\
\hline $\mathrm{E}$ & $\begin{array}{l}\text { Discrete } \\
\text { brightening } \\
\text { (Arcadia) }\end{array}$ & $\begin{array}{l}\text { Bright area in far } \\
\text { encounter }\end{array}$ & $\begin{array}{l}\text { 6F34-6F36, } \\
\text { 7F73-7F75 }\end{array}$ & $\cdots$ \\
\hline F & $\begin{array}{l}\text { Discrete } \\
\text { brightening } \\
\text { (Arcadia) }\end{array}$ & $\begin{array}{l}\text { Bright area in far } \\
\text { encounter }\end{array}$ & $\begin{array}{l}\text { 6F34-6F37, } \\
7 \text { F73-7F76 }\end{array}$ & $\cdots$ \\
\hline $\mathrm{G}$ & $\begin{array}{l}\text { Discrete } \\
\text { brightening } \\
\text { (Tempe) }\end{array}$ & $\begin{array}{l}\text { Bright area in far } \\
\text { encounter }\end{array}$ & $\begin{array}{l}\text { 6F34, 6F35, } \\
\text { 7F72-7F74 }\end{array}$ & $\cdots$ \\
\hline $\mathrm{H}$ & $\begin{array}{l}\text { North polar } \\
\text { haze }\end{array}$ & $\begin{array}{l}\text { Bright area in late far } \\
\text { encounter, most } \\
\text { prominent in the } \\
\text { blue }\end{array}$ & $\begin{array}{l}7 \mathrm{LF}(0223-0257 \\
\text { A frames })\end{array}$ & $\cdots$ \\
\hline I & Thin haze & $\begin{array}{l}\text { Detached limb layers } \\
\text { in near encounter }\end{array}$ & $\begin{array}{l}\text { 7N1, 7N2, } \\
7 \mathrm{~N} 3,7 \mathrm{~N} 5 \\
7 \mathrm{~N} 7,7 \mathrm{~N} 21\end{array}$ & $5-45$ \\
\hline $\mathbf{J}$ & Thin haze & $\begin{array}{l}\text { Detached limb layer in } \\
\text { M7 late far encounter }\end{array}$ & $\begin{array}{l}\text { 7LF }(0301-0315 \\
\text { B frames })\end{array}$ & $15,25,35$ \\
\hline $\mathbf{K}$ & Thin haze & $\begin{array}{l}\text { Detached limb layers } \\
\text { and limb projection } \\
\text { in far encounter }\end{array}$ & 6F39-6F49 & $20-45$ \\
\hline $\mathrm{L}$ & Thin haze & $\begin{array}{l}\text { Detached limb layers } \\
\text { and limb projections } \\
\text { in far encounter }\end{array}$ & $7 F 80-7 F 84$ & $20-30$ \\
\hline $\mathrm{M}$ & Thin haze & Limb projections & 6F39-6F44 & $15-35$ \\
\hline $\mathrm{N}$ & $\begin{array}{l}\text { Thin haze } \\
\text { (questionable: } \\
\text { see text) }\end{array}$ & $\begin{array}{l}\text { Brightening over } \\
\text { desert, merging with } \\
\text { darkening over polar } \\
\text { cap; contrast loss } \\
\text { along cap edge in } \\
\text { near encounter }\end{array}$ & $\begin{array}{c}\text { 7LF }(0223-0319, \\
\text { A-frames }) \\
\text { 7N11, 13 }\end{array}$ & $\cdots$ \\
\hline $\mathrm{O}, \mathrm{P}, \mathrm{Q}$ & $\begin{array}{l}\text { Discrete } \\
\text { brightenings } \\
\text { ( } W \text { cloud })\end{array}$ & $\begin{array}{l}\text { Bright areas in far } \\
\text { encounter }\end{array}$ & $\begin{array}{l}\text { 6F37-6F39 } \\
\text { 7F77-7F79 }\end{array}$ & $<25$ \\
\hline $\mathbf{R}$ & $\begin{array}{l}\text { Discrete } \\
\text { brightenings } \\
\text { ( } W \text { cloud) }\end{array}$ & $\begin{array}{l}\text { Bright area in far } \\
\text { encounter }\end{array}$ & $\begin{array}{l}\text { 6F } 37,6 \mathrm{~F} 38 \\
\quad 7 \text { F78 }\end{array}$ & $<25$ \\
\hline
\end{tabular}

1 Identified by letters appearing in Figure 1.

2 Picture identification code is that of Leighton et al. [1969] except that late far-encounter digital frames of M7 are identified by approximate time of reception and by camera type (A: wide-angle, low-resolution; B: narrow-angle, high-resolution). For example, $7 \mathrm{LF}(0223$, A frame) is the M7 late far-encounter A frame received near $0223 \mathrm{UT}$. 
limb in southern hemisphere longitudes $115^{\circ} \mathrm{W}$ to $240^{\circ} \mathrm{W}$ may extend both eastward and westward and may connect with the layers between longitudes $255^{\circ} \mathrm{W}$ and $265^{\circ} \mathrm{W},(J)$. The bright streaks seen in $6 \mathrm{~F} 42$ to $6 \mathrm{~F} 49$ across Hellas and to the east and west of Hellas (latitudes $30^{\circ}$ to $45^{\circ} \mathrm{S}$, longitudes $195^{\circ} \mathrm{W}$ to $325^{\circ} \mathrm{W}$ ) are not shown in Figure 1 or Table 1, but they may well be manifestations of these same thin haze layers.

The north polar haze is unambiguously identified in the Mariner 7 late far-encounter wideangle frames (A frames), Figure 2, by its bright appearance, particularly in the blue frame. These frames cover the longitude range $320^{\circ} \mathrm{W}$ to $50^{\circ} \mathrm{W}$. North polar haze is inferred in other longitudes in regions that have a bright appearance in the far-encounter frames (B camera, minus-blue filter) similar to that of the green filter late far-encounter frame covering this $320^{\circ} \mathrm{W}$ to $50^{\circ} \mathrm{W}$ region. Thus the identification of north polar haze in other longitudes is less certain. Photometrically decalibrated pictures reveal little apparent change in the distribution of this haze during the 5-day interval between Mariner 6 and Mariner 7. They also reveal that this haze, which appears brightest in the blue against the red background of the planet, is essentially white.

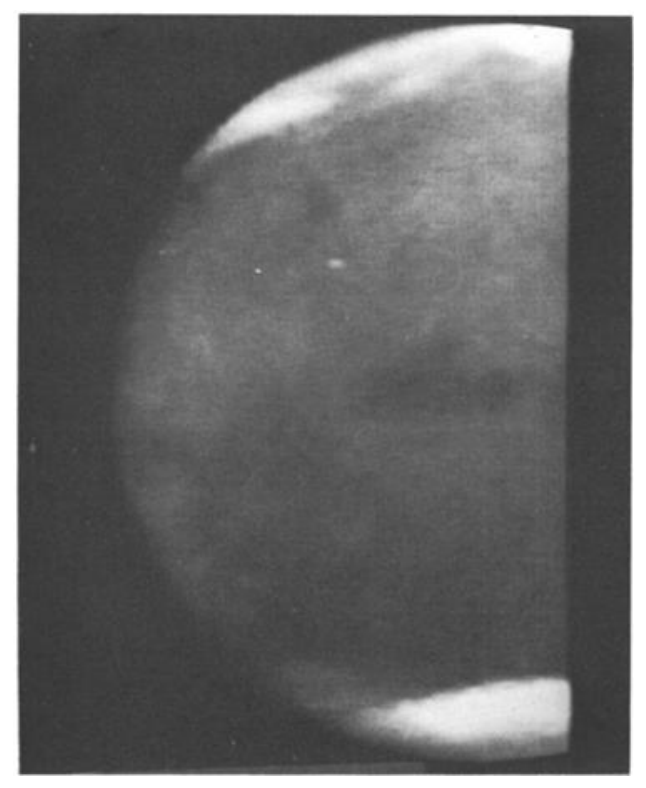

Fig. 2. M7 late far-encounter A frame received near 0248 UT, blue filter (left). M7 late far-
encounter A frame received near 0249 UT, green filter (right).

Fig. 2. M7 late far-encounter A frame received near $0248 \mathrm{UT}$, blue filter (left). M7 late far-
encounter A frame received near $0249 \mathrm{UT}$, green filter (right).

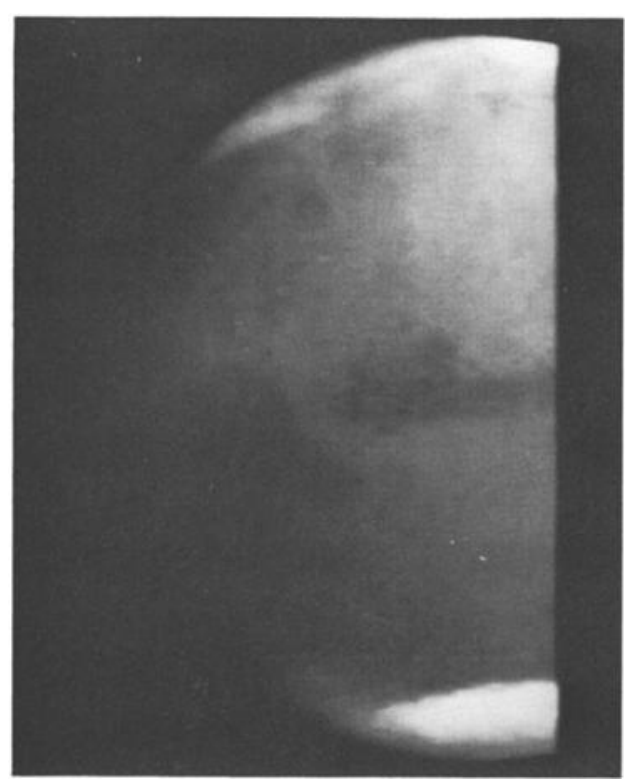

Thin haze $C$ in Figure 1 and Table 1 corresponds closely in location with the north polar haze and may be related to it.

\section{Thin Hazes}

The most frequent and most secure indentification of thin hazes is from their appearance as detached layers on the limb. Figure 3 is a portion of frame $6 \mathrm{~F} 49$ with such a detached layer over Hesperia and Mare Cimmerium, and a portion of frame 7F82, showing a limb projection contiguous with short detached layers on either side typical of region $L$ in Figure 1. Frame 7LF (0314), a B frame (Figure 4), shows the complex structure above the limb in region $J$. This picture contains only digital data sampled at every seventh picture element along each TV line. It was processed by holding the intensity at each sample point constant for the next six unsampled elements along each line, thus producing the 'stairstep' appearance. In addition, it still contains a considerable amount of electronic system noise and has not been photometrically decalibrated. Nevertheless, the layered structure above the limb is real and appears in most of the late far-encounter M7 B frames. Three distinct layers are generally seen, although the upper one is usually quite faint. They are approximately 10 

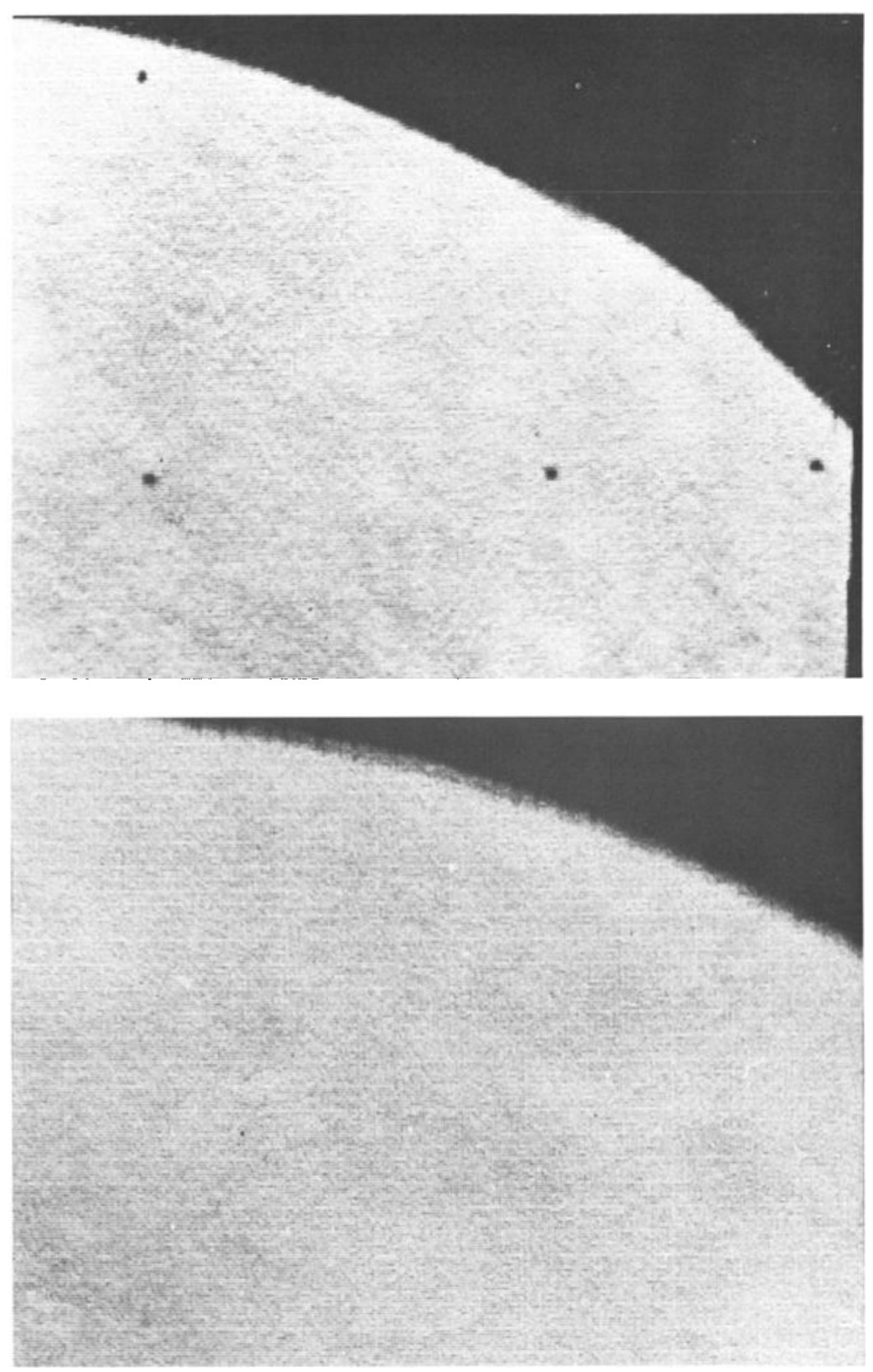

Fig. 3. Portion of 6 F49 showing detached thin haze layer on the limb (top). Portion of 7F82 showing limb projection inferred to be thin haze (bottom). 


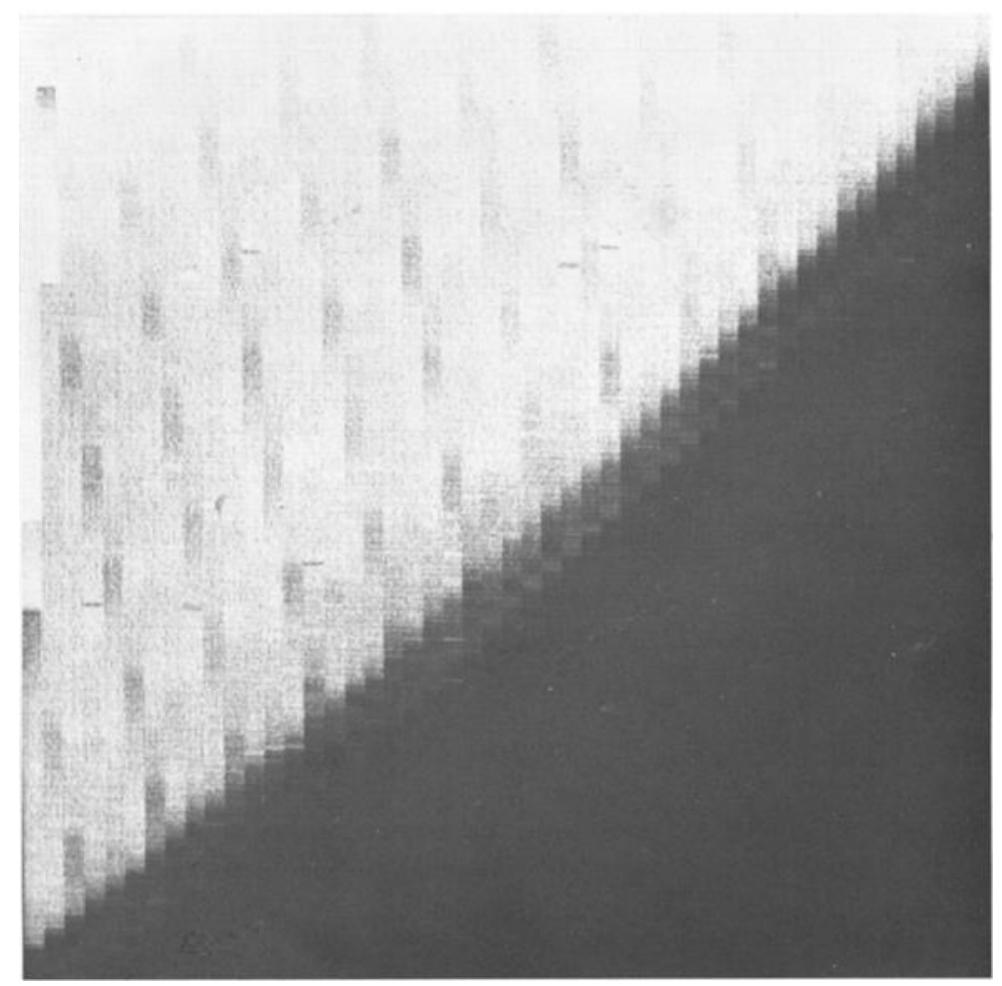

Fig. 4. Portion of 7LF (0314 UT) showing detached layers above the limb.

$\mathrm{km}$ apart in height; the lowest layer is estimated to be 10 or $15 \mathrm{~km}$ above the surface. (Resolution normal to the limb is $4 \mathrm{~km}$ for this frame.)

In most of these cases, the haze is inferred to be optically thin for normal incidence viewing because of its detached appearance. Unless the haze were of very limited horizontal extent and happened to be situated exactly on the limb, it would not appear separated from the planet. The appearance of the haze in several consecutive pictures and the large extent of the haze along the limb in some pictures show that the haze is not of limited horizontal extent.

There is close correspondence, both in appearance and in location of haze $L$ seen in M7 frames, and haze $M$ seen in M6 frames. The thinner haze $K$ seen clearly in M6 frames is not evident in M7 frames, but this could be due to differences in the two cameras rather than to real changes on Mars. The M6 B camera was more sensitive at the lowillumination levels of these detached layers.

Analysis of haze layers in Mariner 7 nearencounter limb frames. The most striking examples of thin haze appearing on the limb were seen in frames $7 \mathrm{~N} 1,7 \mathrm{~N} 2,7 \mathrm{~N} 3,7 \mathrm{~N} 5,7 \mathrm{~N} 7$, and $7 \mathrm{~N} 21$ [Leighton et al., 1969]. Figure 5 shows contours of reflectance relative to a perfectely reflecting lambert surface normal to the sun's rays at the position of Mars. The contours are superimposed on the corresponding portion of highresolution frame $7 \mathrm{~N} 2$.

For an optically thin layer above a surface of sufficiently low reflectivity that atmospheric scattering of light reflected from the surface can be neglected (a satisfactory approximation for Mars), the reflectance $R$ due to the scattering layer [Young, 1969] is:

$R=\frac{\pi B}{F_{0}}=\left[1-\exp \left(-M \tau_{e}\right)\right] \cdot P^{\prime}(\alpha) / 4$

Here $B$ is the irradiance of the layer, $F_{0}$ is the solar flux, $\tau_{e}$ is the normal incidence optical depth for extinction due to the layer, $M$ is the air-mass factor, the number of equivalent normal incidence traverses of the layer along the line of sight, and $P^{\prime}(\alpha)$ is the product of the single scattering albedo and the phase function, depending on phase angle $\alpha$. For nonabsorbing 
Rayleigh scattering particles, $P^{\prime}$ is

$$
P_{r}^{\prime}=(3 / 4)\left(1+\cos ^{2} \alpha\right)
$$

Since it is of interest to compare the scattering above the limb with Rayleigh scattering, we shall consider the ratio $P^{\prime} / P_{r}^{\prime}$, and in the following analysis we assume that $P^{\prime}$ is independent of height. In the M7 limb frames, the haze is seen in backscattering $\left(\alpha \simeq 44^{\circ}\right)$.

Direct inversion of (1) to find the height dependence of $\tau_{e}$ is complicated if $M \tau_{e}$ is large anywhere in the layer. In portions of the layer where $M \tau_{c}$ is large, the value of $R$ is nearly equal to $P^{\prime} / 4$, but it is difficult to distinguish regions of large $M \tau_{e}$ and small $P^{\prime}$ from regions with larger $P^{\prime}$ and small, slowly varying $M \tau_{e}$. The problem is further complicated by the difficulty of precisely locating the true planetary limb. Figure 6 shows reflectance profiles across the same part of the limb (near the west edge of 7N2) for frames $7 \mathrm{~N} 1,7 \mathrm{~N} 2,7 \mathrm{~N} 3$, and $7 \mathrm{~N} 5$. Frames $7 \mathrm{N1}$, $7 \mathrm{~N} 3$, and 7N5 were taken through blue, green, and red filters, respectively. The geometrical characteristics and reflectance values of the haze layer are very similar in all four profiles despite the resolution difference between $7 \mathrm{~N} 2$ and $7 \mathrm{~N} 1$, $7 \mathrm{~N} 3$ and $7 \mathrm{~N} 5$ (about $0.29 \mathrm{~km}$ per pixel in $7 \mathrm{~N} 2$, and $2.9 \mathrm{~km}$ per pixel in $7 \mathrm{~N} 1,7 \mathrm{~N} 3$, and $7 \mathrm{~N} 5$ ), and despite the red color of the planet itself. The difficulty in locating the true limb is also apparent from Figure 6, since it is not clear whether the decrease in reflectance between $7 \mathrm{~N} 2$ pixels 160 and 220 is due to limb darkening over the face of the planet or to haze of decreasing brightness above the limb. In the latter case, one might assume that the true limb is at the beginning of the steep falloff in reflectance near $7 \mathrm{~N} 2$ pixel 160 , in which case the peak of the scattering layer lies about $23 \mathrm{~km}$ above the surface, and there is substantial scattering below the sharply peaked layer, apparently down to the surface itself. (Atmospheric molecular scattering is negligible, contributing a relative reflectance of not more than 0.02 in $7 \mathrm{~N} 2$.)

Alternatively, we may use the fact that A frames $7 \mathrm{~N} 1,7 \mathrm{~N} 3$, and $7 \mathrm{~N} 5$ show no obvious haze layer on the east (right) side of the frames. If we assume that profiles in this portion of the frame are due to the true limb plus any uncorrected instrumental effects, we can obtain the profile of the scattering layer by subtracting these 'background' profiles. This procedure involves subjective shifting of the profiles to obtain best fits of the hazy and 'clean' profiles near the beginning of the sharp brightness decrease. Thus, the results are perhaps not very reliable. Figure 7 shows the results of such a background subtraction. In fitting $7 \mathrm{~N} 1$, allowance was made for the fact that the west side of $7 \mathrm{~N} 1$ appears to be about 0.015 reflectance units brighter than the east side over the face of the planet. Figure 7 shows that the maximum of the haze layer may be reasonably interpreted to lie between 12 and $22 \mathrm{~km}$ above the surface. This interpretation also requires that there be additional scattering from well below the apparent peak of the layer.

A third approach is to assume that the brightness decrease between $7 \mathrm{~N} 2$ pixels 160 and 220

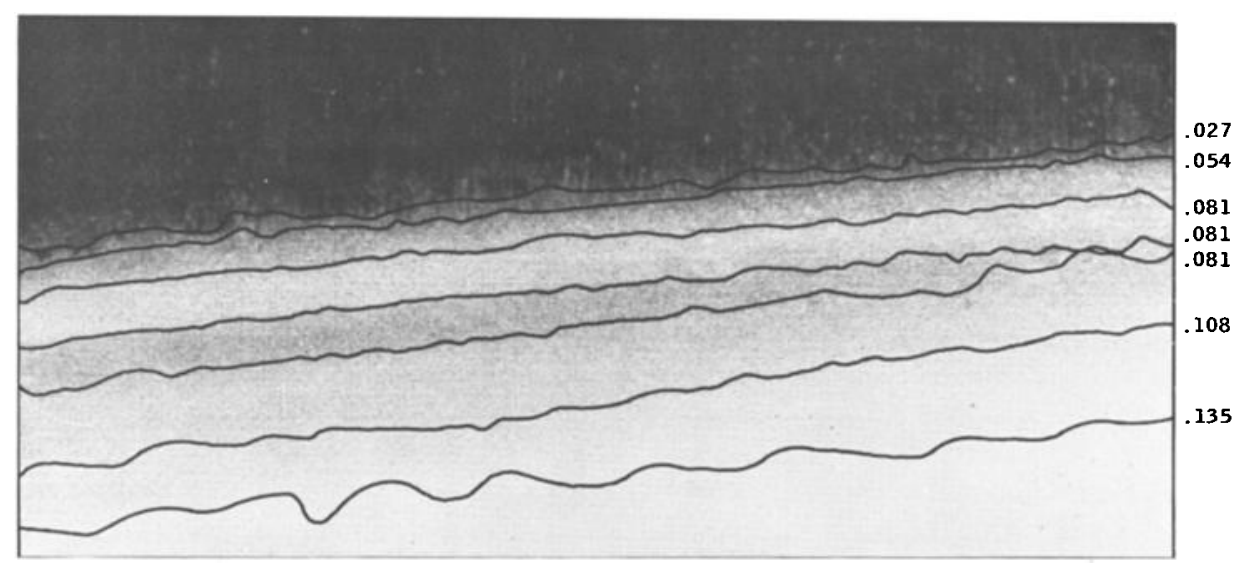

Fig. 5. Relative reflectance contours superimposed on a portion of high-resolution frame 7N2. 


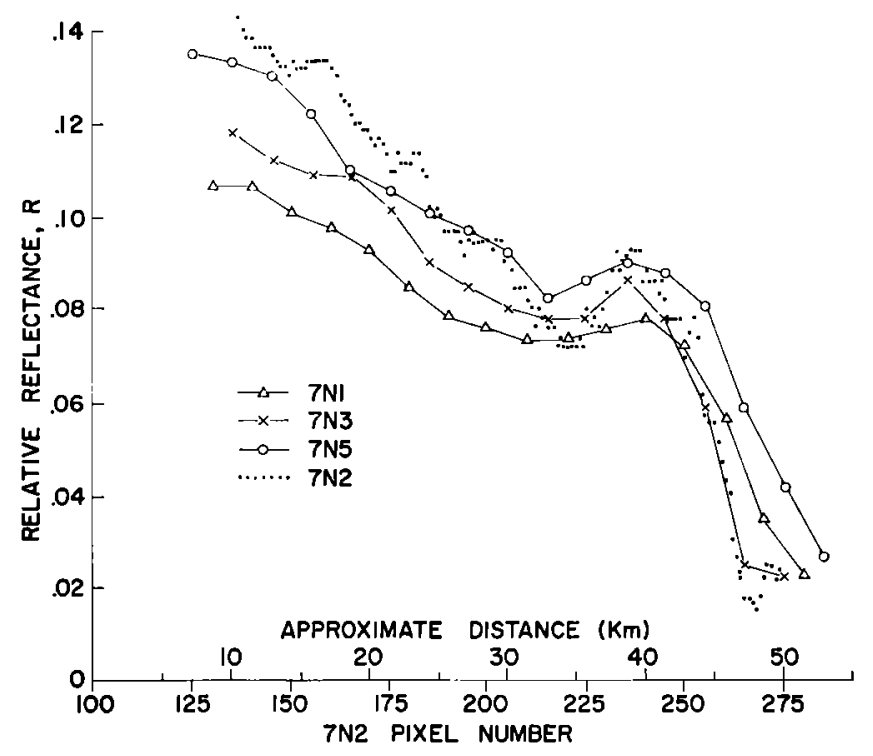

Fig. 6. Relative reflectance profiles across the limb for $7 \mathrm{~N} 1$ (blue filter), $7 \mathrm{~N} 2$ (minus-blue filter), 7N3 (green filter), and 7N5 (red filter).

(Figure 6) is due to limb darkening of the planetary surface with an isolated haze layer above the surface. Two models for such an elevated haze layer that bound a wide range of possibilities are: a layer of uniform density of scattering centers with base at height $h$ confined to a region of thickness $d$, and an exponential layer with sharp base at $h$, and scale height $d$. For the uniform layer, the height dependence of the air mass factor $M$ is

$$
\begin{array}{ll}
M(z)=M_{*}|y|^{1 / 2}\left\{\left(1+|y|^{-1}\right)^{1 / 2}-1\right\} & z<h \\
M(z)=M_{*}(1-y)^{1 / 2} & z \leqq h
\end{array}
$$

For the exponential layer,

$$
\begin{array}{ll}
M(z)=(\sqrt{ } \pi / 2) M_{*}\left\{1-\operatorname{erf}\left(|y|^{1 / 2}\right)\right\} & z<h \\
M(z)=(\sqrt{ } \pi / 2) M_{*} e^{-y} & z \leqq h
\end{array}
$$

where $M_{*}=2(2 a / d)^{1 / 2}, y=(z-h) / d$, and $a$ is the planetary radius.

The average positions and reflectance values of the minimum (pixel $220, R=0.072$ for the $7 \mathrm{~N} 2$ profile of Figure 6), the maximum (pixel 238, $R=0.093$ in Figure 6), and the point at which reflectance above the peak falls to one-half the value at the peak, were used to determine $h, d, \tau_{e}$, and $P^{\prime} / P_{r}{ }^{\prime}$ for these two models for each of four segments spanning across the limb of $7 \mathrm{~N} 2$. Results are given in Table 2. An example of the fit of $7 \mathrm{~N} 2 \mathrm{limb}$ data to the models is shown in Figure 8. The picture that emerges is of an isolated elevated layer based about $5 \mathrm{~km}$ above the surface, with most of the scattering from below $10 \mathrm{~km}$, a normal incidence optical thickness of at least 0.05 , and phase function less than $1 / 3$ that of a Rayleigh scatterer. The latter two conclusions result from the assumption of a sharply based isolated layer and the observation that the ratio of reflectance at the minimum to that at the layer peak is high.

These three approaches lead to significantly different interpretations of the layer, but two rather firm conclusions can be drawn. At least some of the scattering must be due to scattering particles that are not solid carbon dioxide. This follows from our conclusions that the reflectance profiles can be explained either by an isolated scattering layer based $5 \mathrm{~km}$ above the surface, or by a scattering layer with a maximum between 12 and $23 \mathrm{~km}$ above the surface, but with additional scattering from much lower heights. Theory and observation indicate that $\mathrm{CO}_{2}$ condensation does not take place below $20 \mathrm{~km}$ at the time and place of the M7 limb frames [Gierasch and Goody, 1968; Rasool et al., 1970]. Our second 


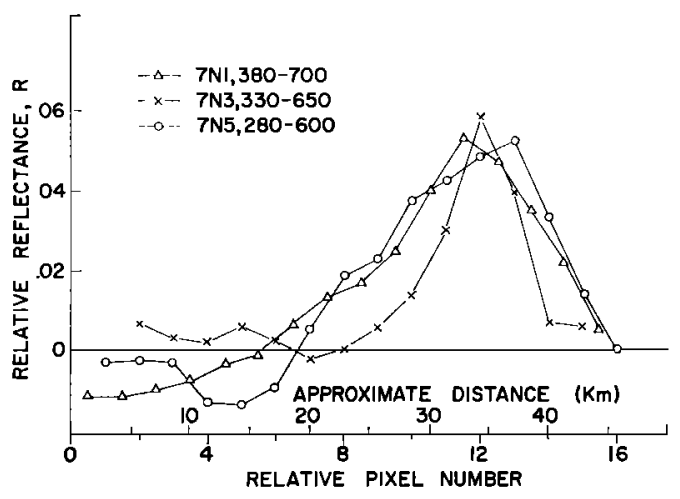

Fig. 7. Difference plots for the indicated line pairs crossing the limb in $7 \mathrm{~N} 1,7 \mathrm{~N} 3$, and $7 \mathrm{~N} 5$. The distance scale is accurate for $7 \mathrm{~N} 1$, approximate for $7 \mathrm{~N} 3$ and $7 \mathrm{~N} 5$.

conclusion is that the scattering is not Rayleigh scattering. If the haze is optically thick along the line of sight, Rayleigh scattering would give

$$
R \simeq P_{r}^{\prime} / 4=0.31
$$

but we obtain a maximum value of $R \simeq 0.09$. On the other hand, if the haze is not optically thick along the line of sight but produces Rayleigh scattering, it would appear blue. Figure 6 shows no indication of blue color. Our previous assertion [Leighton et al., 1969] that this haze appears to have an approximate $\lambda^{-2}$ wavelength dependence was based on a rough preliminary decalibration of the data and is incorrect.

Other evidence for haze. Figure 2 shows a region near the southwest limb between longitudes $30^{\circ} \mathrm{W}$ and $50^{\circ} \mathrm{W}$ in which brightening over the desert adjacent to the polar cap merges into darkening over the cap. The eastern portion of this region is seen in $7 \mathrm{~N} 11$ and $7 \mathrm{~N} 13$ (region $N$ in Table 1). The contrast between cap edge and desert is much smaller at more oblique viewing angles near the bottom of frame $7 \mathrm{~N} 11$ than at the more nearly vertical viewing angles near the top (Figure 9). Although these contrast variations might be caused by haze, they could also be produced by surface albedo variations and by differences in the photometric function between the polar cap and the adjacent desert. Figure 9 shows profiles of relative reflectance over the polar cap and adjacent desert, plotted as a function of relative air mass $M$. Although the profiles show the contrast variation, the desert area does not brighten steadily with increasing $M$, as one would expect for a thin haze.

We therefore tentatively interpret the contrast variation seen in this region as a combination of an albedo variation over the desert and darkening over the polar cap due to a photometric function that is sensitive to the solar incidence angle. (The solar incidence angle increases steadily with increasing $M$ across frame 7N11.)

Thin hazes may extend over the polar cap at some places; however, we suggest that a reasonable interpretation of the general darkening seen around the south-pole limb in far encounter may be that this is a consequence of the surface photometric function and not of general atmospheric haze. Such an interpretation is supported by the clarity of detail seen at near encounter near the south-pole terminator and by the low-illumination levels (relative reflectance $\lesssim 0.015$ ) near the terminator itself (frame $7 \mathrm{~N} 19$, blue filter).

The blue haze question. Most of the evidence for thin haze discussed above has no bearing on the question of whether the surface of Mars is significantly obscured by a blue haze, since, in most cases, haze is identified in pictures taken with the minus-blue filter of the high-resolution cameras. Mariner 7 late far-encounter- and nearencounter-limb frames include some blue-filter frames for which color comparisons are possible. These pictures show the thin haze $I$, the questionable area $N$, and the polar haze $H$. The polar haze has long been observed and recognized as a phenomenon distinct from the contrast loss in blue, which has sometimes been attributed

TABLE 2. Parameters from Model Fitting of Limb Haze $7 \mathrm{~N} 2$

\begin{tabular}{|c|c|c|c|c|c|}
\hline \multirow[b]{2}{*}{ Parameter } & \multicolumn{4}{|c|}{ Segment Number } & \multirow[b]{2}{*}{ Average } \\
\hline & 1 & 2 & 3 & 4 & \\
\hline \multicolumn{6}{|c|}{ Unıform Layer } \\
\hline$h, \mathrm{~km}$ & 5.6 & 53 & 44 & 4.4 & 4.9 \\
\hline$d, \mathrm{~km}$ & 69 & 59 & 9.0 & 61 & 70 \\
\hline$\tau_{e}$ & 0044 & 0058 & 0085 & 0.059 & 0.062 \\
\hline$P^{\prime} / P_{r}^{\prime}$ & 033 & 0.30 & 0.28 & 0.30 & 030 \\
\hline \multicolumn{6}{|c|}{ Exponential Layer } \\
\hline$h, \mathrm{~km}$ & 56 & 5.3 & 44 & 4.4 & 4.9 \\
\hline$d, \mathrm{~km}$ & 22 & 16 & 3.3 & 2.0 & 23 \\
\hline & 0.13 & 023 & 011 & 014 & 0.15 \\
\hline$P^{\prime} / P_{r}{ }^{\prime}$ & 030 & 029 & 0.28 & 029 & 029 \\
\hline
\end{tabular}




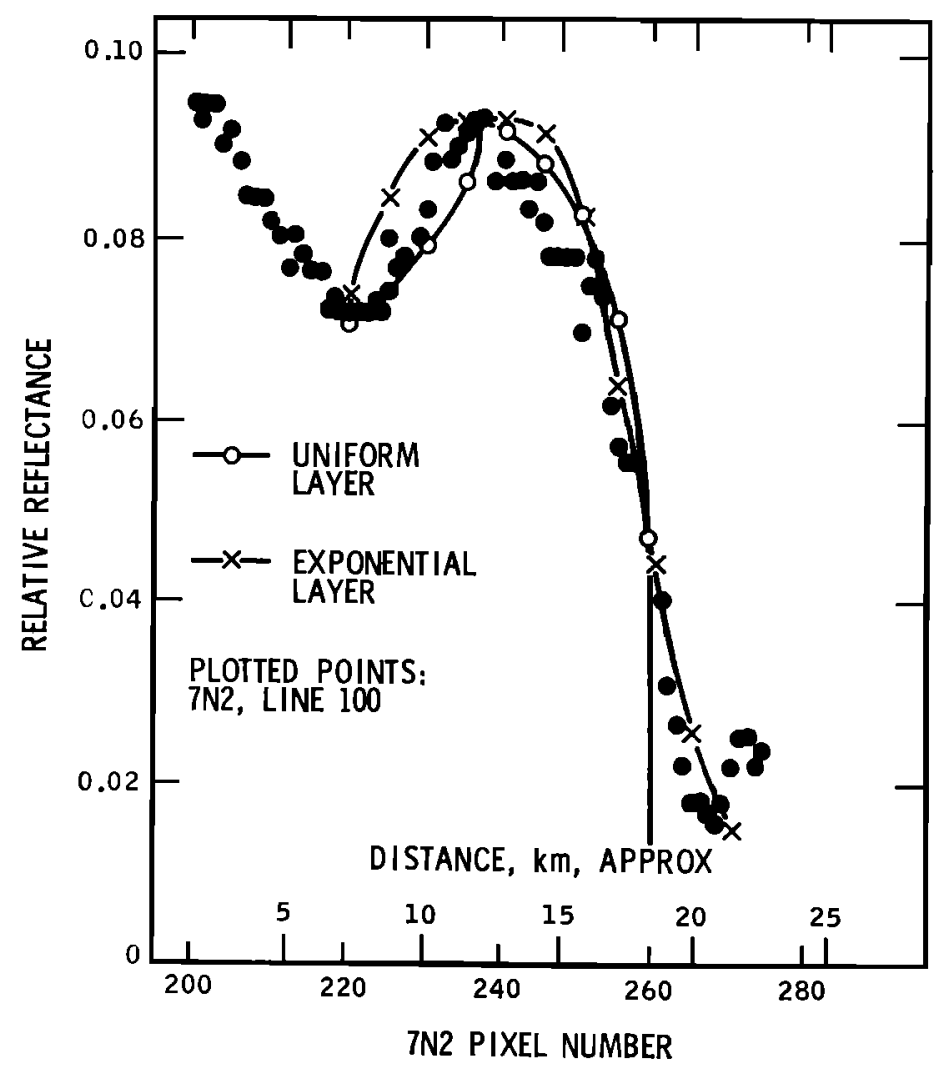

Fig. 8. Comparison between the limb profile reflectance values of $7 \mathrm{~N} 2$, line 100, and profiles obtained by fitting the uniform layer model and the exponential layer models to these data using the procedure described in the text.

to a blue haze. The thin haze layer $I$ is not as bright in the blue as the face of the planet even when the layer is viewed tangentially. If we adopt the parameters of Table 2 , haze $I$ would contribute less than $12 \%$ to the brightness of the planet in blue when viewed at normal incidence. This is far too little to account for the contrast loss attributed to blue haze. The extensive hazes $J, K, L$, and $M$ are optically thin in minus-blue-filter frames, and if they have the same color characteristics as haze $I$, they would also be incapable of producing a 'blue haze' effect.

The results of this paper depend on light scattered by the atmosphere, and thus are not relevant to possible atmospheric absorption. The best evidence that neither atmospheric absorption nor scattering obscures the surface in blue light remains the near encounter A frames. The contrast between flat surfaces and sloping crater walls is similar in pictures taken with blue, green, and red filters taken at comparable solar elevation angles. On the other hand, the contrast between light and dark albedo markings decreases from red to green and from green to blue [Leighton et al., 1969].

\section{Discrete Bright Features}

Processed Mariner pictures were examined for discrete bright features that could be optically thick haze or clouds. With the exception of the features discussed below, none was detected.

South polar cap region. M7 A frames 7N15, $7 \mathrm{~N} 17$, and $7 \mathrm{~N} 19$ show a number of large irregular patches that are brighter than the surrounding areas of the cap [Sharp et al., 1971]. These features have no obvious shadows and do not exhibit any of the structure usually found in clouds formed by such conventional meteorological processes as large-scale uplift or convection. 
High-resolution frames $7 \mathrm{~N} 14,7 \mathrm{~N} 16$, and $7 \mathrm{~N} 18$ reveal no cloudlike features, but they do show many areas of positive relief and apparent variations in brightness of surface material. As processing improved the quality of the pictures, some of the bright patches in the A frames, such as the mottled bright patch in the southwest portion of $7 \mathrm{~N} 17$, began to take on more of the appearance of topographic features.

Irregular bright patches just outside the cap edge (7N11, $7 \mathrm{~N} 12$, and $7 \mathrm{~N} 13$ ) also deserve consideration as possible clouds. Again, however, most such features seen at the highest available resolution (7N12) can be identified as topographic features, for example, as apparent frost deposits related to clusters of overlapping craters. We believe, therefore, that none of the features over or near the south polar cap can be convincingly identified as clouds.

North polar cap region. Features $E, F$, and $G$ (Figure 1 and Table 1) were seen in unprocessed M6 and M7 far-encounter frames and are prominent in the processed versions. These are the Arcadia ( $E$ and $F$ ) and Tempe $(G)$ 'clouds,' often recorded on telescopic photographs taken in blue and green light. They appear in identical locations in M6 and M7 pictures, but their shapes have changed, $F$ and $G$ being somewhat smaller
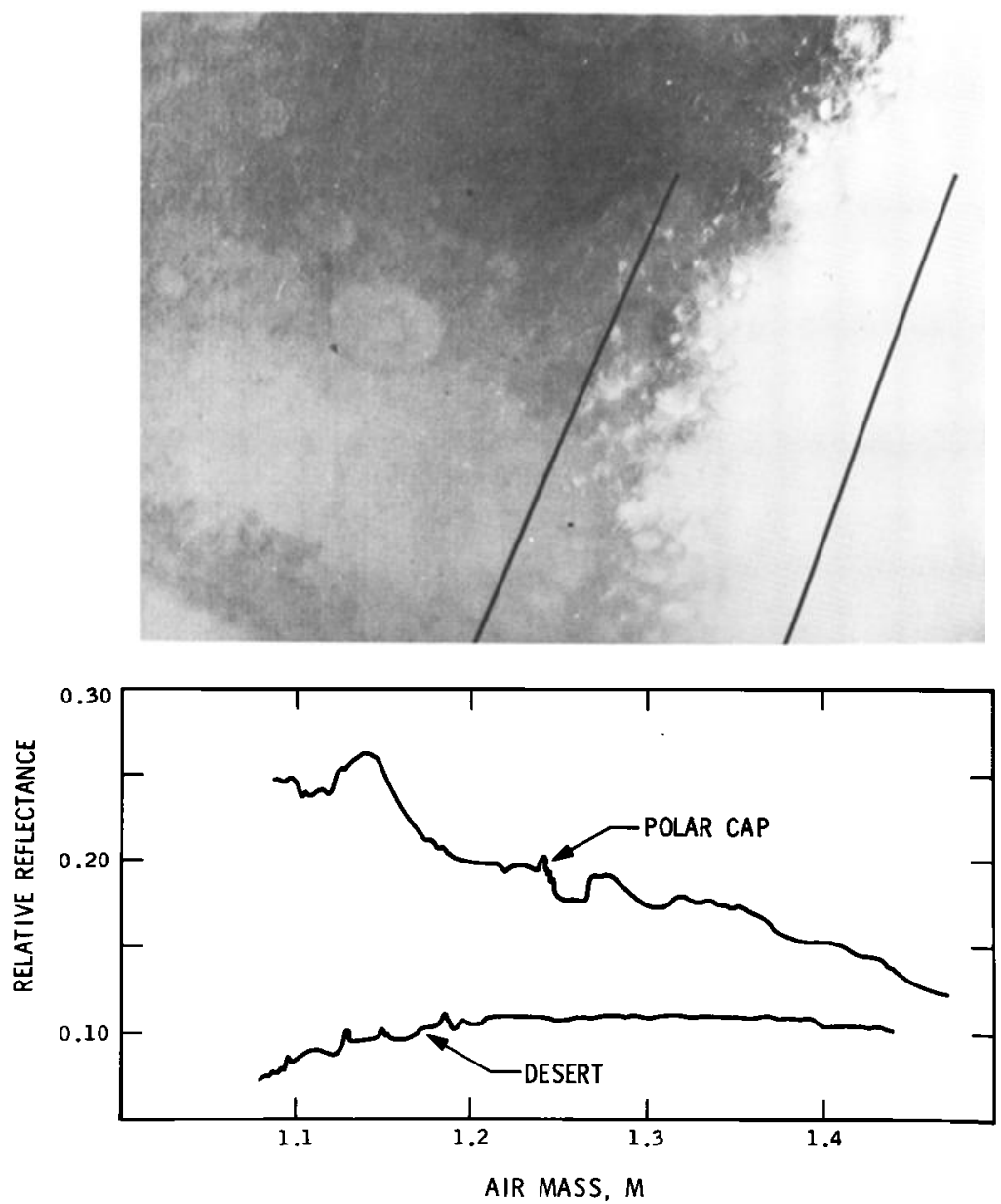

Fig. 9. Photometrically decalibrated version of $7 \mathrm{~N} 11$ showing contrast loss at increasingly oblique angles $(t o p)$. Profiles of relative reflectance along the indicated lines are shown as a function of air mass, $M$ (bottom). 
in M7 than in M6. Their apparent brightness has also changed: they are about $30 \%$ brighter in the M6 pictures than in the M7 pictures (Figure 10). Such an apparent change could be due to differences in the two camera systems, intrinsic brightness change of the features, or partial veiling of the features by atmospheric haze at the time of the M7 pictures. The first of these possibilities can be ruled out on the following grounds. The contrast between the objects and their surroundings is greater in M6 than in M7 pictures, even though the contrast of comparably bright objects seen in far encounter, such as the south polar cap, is greater in M7 than in M6 pictures. The brightness of surrounding regions is about the same in the M6 and M7 frames showing $E, F$, and $G$. Possible explanations for $E, F$, and $G$ include surface-frost deposits, clouds, or thicker portions of the prevailing north polar haze; the nearly constant brightness of these features as they approach the limb suggests a surface phenomenon (Figure 10).

Tropical region: the ' $W$ cloud'. Features $O, P$, $Q$, and $R$ comprise elements of the ' $W$ cloud' frequently seen by ground-based observers (Figure 11). These features exhibit a different behavior than that of north polar features, $E$, $F$, and $G$. Whereas $E, F$, and $G$ maintain constant brightness during at least the afternoon portion of the day, $O, P, Q$, and $R$ brighten

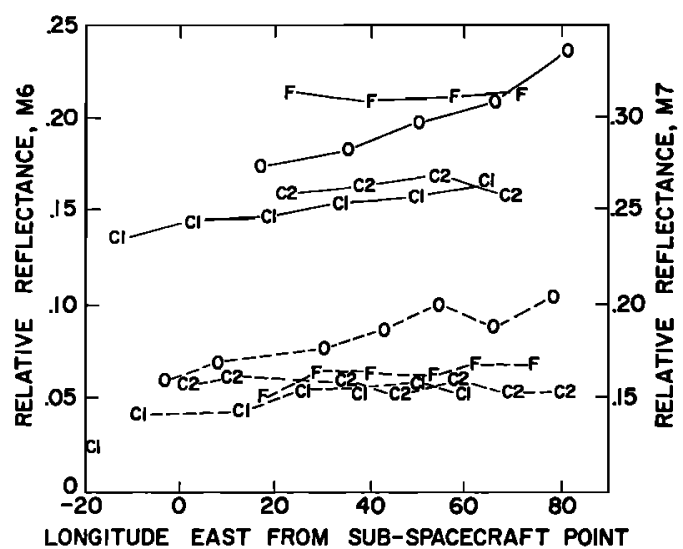

Fig. 10. Variation in relative reflectance of discrete bright objects $F$ (latitude $46^{\circ} \mathrm{N}$, longitude $261^{\circ} \mathrm{W}$ ) and $O$ (latitude $1^{\circ} \mathrm{N}$, longitude $248^{\circ} \mathrm{W}$ ), and in two 'normal' control points $C 1$ (latitude $10^{\circ} \mathrm{N}$, longitude $224^{\circ} \mathrm{W}$ ), and $C 2$ (latitude $13^{\circ} \mathrm{S}$, longitude $244^{\circ} \mathrm{W}$ ). Solid curves, M6; dashed curves, M7. steadily during the afternoon (Figure 10). They are also brighter in M6 frames than in M7 frames. The brightness of these features (relative reflectance about 0.06 greater than surrounding points at air masses $M \sim 3$ ) indicates that they are qualitatively different from the thin limb hazes seen in frames $7 \mathrm{~N} 1,7 \mathrm{~N} 3,7 \mathrm{~N} 5$, and $7 \mathrm{~N} 7$ $(R \sim 0.09$ at $M \sim 50)$. They may be optically thicker or have a larger backscattering phase function than the M7 limb haze, or they may vary in scattering power with local time.

Figure 12 shows areas of diserete bright clouds reported by Martin and Baum [1969] superposed on $7 \mathrm{~F} 74$. Thirty-one out of 52 of the stationary discrete bright features identified in their study occur within the envelopes shown in Figure 11, as do features $F, G, O, P, Q, R$, and the ringed Feature, Nix Olympica. Elements $O, P$, and $Q$ also exhibit multiple-ringed structure similar to Nix Olympica prior to their brightening phase (Leighton et al. [1969]; e.g. see frame 7F74). Similar very large structures are evident throughout the tropical envelopes of the Martin and Baum study shown in Figure 12 but are not evident elsewhere. There appears to be a close connection between these large multiple-ringed structures and variable brightening phenomena.

A recent study of discrete bright martian clouds by Dean and Smith (unpublished data, 1970) indicates that certain features exhibit seasonally dependent meteorological activity. This study further points out that, in a general sense, bright cloud activity should have been quiescent at the time of Mariner 6 and 7 encounter, the notable exception being parts of the $W$ cloud.

Comments on water-vapor exchange processes as an interpretation for the $W$ cloud features. The absence of observable limb layers or projections when $O, P, Q$, or $R$ are on the limb leads us to infer that the upper portions of these features are probably not higher than $25 \mathrm{~km}$. This inference, together with their tropical location, makes it very unlikely that they are a consequence of $\mathrm{CO}_{2}$ condensation.

We reported earlier that these features showed no apparent convective structure [Leighton et al., 1969]. Processed versions of 7F76 and 77 reveal some patchiness in feature $O$, but the development in time does not resemble that of large scale convective regions in the earth's atmosphere. Whether convective or not, their 


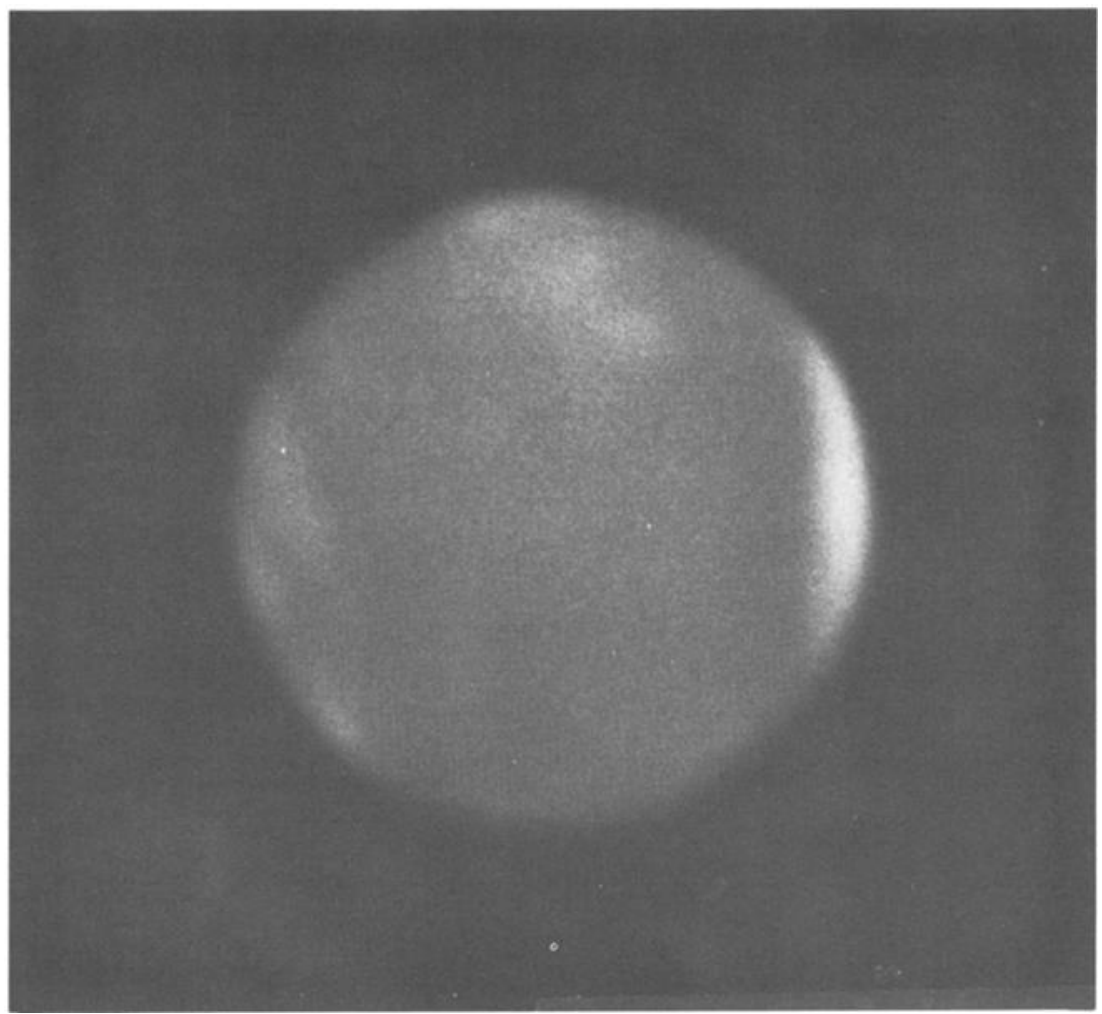

Fig. 11. Ground-based photograph of Mars taken on June 13, 1969, at 10:15 UT at the New Mexico State University Observatory (blue filter). The bright features near the east (right) limb are elements of the $W$ cloud.

repeated occurrence in fixed locations over many years, their apparent association with a unique surface morphology, and the argument against $\mathrm{CO}_{2}$ condensation as a mechanism, make it tempting to speculate that they are indications of persistent water vapor exchange between the atmosphere and the surface.

The fact that water would tend to be rapidly removed from tropical regions to be preferentially trapped out at higher latitudes, both on seasonal and very long time scales, places severe constraints on any model of such an exchange process. This can be demonstrated by means of a simplified exchange model. Suppose that there is a slowly varying upward flux of vapor $F_{m}$ through the Mars soil. Such a flux would be driven by the gradient between $e_{s}$, the saturation vapor pressure at the subsurface moisture source (perhaps a permafrost layer), and $e_{a}$, the atmospheric vapor pressure. Then, if $D_{m}$ and $\pi$ are, respectively, the diffusivity of water vapor in the soil and the soil porosity, and if $z$ is the source depth,

$$
F_{m}=\left(D_{m} / R_{w} T z\right)\left(e_{s}-e_{a}\right)=\rho \pi \frac{\partial z}{\partial t}
$$

where $\rho$ is the density of ice, $R_{w}$ is the gas constant for water, and $T$ is the soil temperature. If the source is at the surface at time $t=0$, time integration gives:

$$
\begin{aligned}
z(t) & =\left[\frac{2 D_{m}\left(e_{s}-e_{a}\right)}{R_{w} T \rho \pi}\right]^{1 / 2} t^{1 / 2} \\
F_{m}(t) & =\left[\frac{\rho \pi}{2 R_{w} T}\left(e_{s}-e_{a}\right)\right]^{1 / 2} t^{-1 / 2}
\end{aligned}
$$

To estimate the maximum time for which $F_{m}$ could provide a significant source, we take upper limit values of $D_{m}=10 \mathrm{~cm}^{2} / \mathrm{sec}, \pi=1$, and set $e_{a}=0$ and $e_{s}=e_{s}\left(220^{\circ} \mathrm{K}\right)$, corresponding to the mean radiative equilibrium temperature of the soil. We find that the time required to draw 


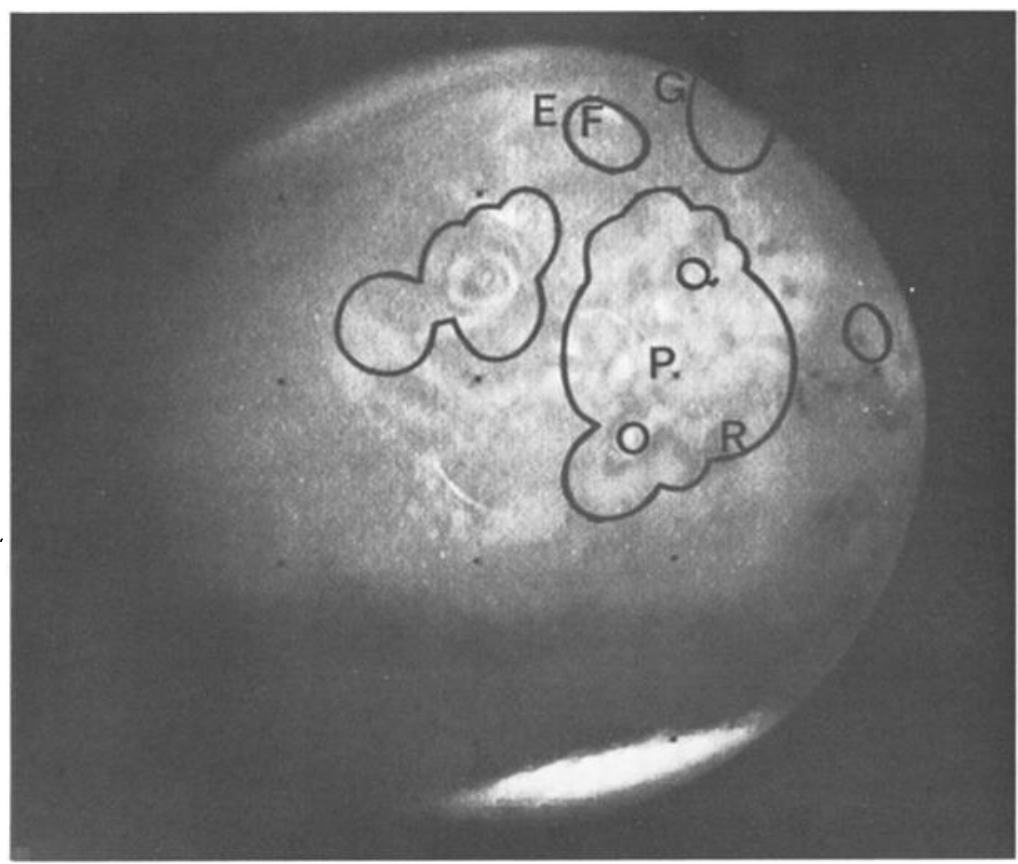

Fig. 12. Envelopes of observed stationary discrete bright features in the Tempe, Tractus Albus, Candor, and Nix Olympica regions, as determined by Martin and Baum [1969]. The envelopes are plotted on 7F74. Locations of $E, F, G, O, P, Q$, and $R$ are also shown.

the source down to such a depth that the flux is less than the very small value $10^{-4} \mathrm{~g} / \mathrm{cm}^{2}$-day is less than 400 years. Such a short-lived source would be very unlikely to be observable. This argument does not preclude the existence of tropical subsurface permafrost layers. After a comparatively short period of time, such layers would be both protected and unobservable by their exchange effects because of the slowness of diffusion.

If the assumption that $e_{s}$ is determined by the local radiative equilibrium temperature is relaxed, the situation could be different. Such a situation could arise if there is a mean heat flux and temperature gradient in the soil. In this case moisture driven upward by sublimation at comparatively high temperatures deep in the soil could continually recondense closer to the surface and maintain a steady source depth and steady flux rate over long time periods. Assume steady fluxes with constant moisture diffusivity and thermal conductivity $K_{h}$ above the top of the saturated layer at temperature $T_{s}>T_{a}$. Then, the heat flux $F_{h}$ satisfies

$$
F_{h}=K_{h}\left(T_{s}-T_{a}\right) / z
$$

At the top of the saturated layer $e_{s}=e_{s}\left(T_{s}\right)$, the saturation vapor pressure at $T_{s}$. Just below the upper edge of the saturated layer, the rate of increase of vapor pressure with temperature (and with depth) must be greater than it is just above the edge. This is because condensation will reduce the porosity of the saturated layer and hence will reduce the ratio $D_{m} / K_{h}$. It follows that the ratio of the gradient of vapor pressure to that of temperature must increase downward across the upper edge of the saturated layer if the fluxes of heat and moisture are constant. Furthermore, latent heat release below the top of the saturated layer will constrain the vapor pressure and temperature to satisfy the ClausiusClapeyron equation. Combining these constraints with the requirement that temperature and vapor pressure are continuous across the top of the saturated layer leads to the following requirement for a steady state:

$$
\left(\frac{e_{s}-e_{n}}{T_{s}-T_{a}}\right)=\left(\frac{d e}{d T}\right)_{s}
$$

where $(d e / d T)_{s}$ is the slope of the saturation vapor pressure curve at the temperature of the 
top of the saturated layer so that $e_{s}$ and $T_{s}$ are uniquely determined by the choice of $e_{t}$ and $T_{a}$. Combining (5), (8), and (9),

$$
\left.F_{m}=\frac{D_{m}}{R_{w}} \frac{d K_{h}}{d T}\right)_{s} F_{h}
$$

To obtain an upper limit estimate for this flux, let $D_{m}=10 \mathrm{~cm}^{2} / \mathrm{sec}, K_{h}=2.5 \times 10^{-4}$ $\mathrm{w} / \mathrm{cm}-{ }^{\circ} \mathrm{K}$ consistent with the results of Neugebauer et al. [1969], $T_{a}=220^{\circ} \mathrm{K}, e_{a}=0$. We obtain:

$$
F_{m} \sim 2 \times 10^{-4}\left(F_{h} / F_{h e}\right) \mathrm{gm} / \mathrm{cm}^{2}-\text { day }
$$

where $F_{h e} \sim 10^{-6} \mathrm{cal} / \mathrm{cm}^{2}$-sec, approximately the mean terrestrial heat flux value [Anderson, 1969]. Thus, if the heat flux in these isolated Mars locales exceeds $F_{h e}$, possibly significant rates of water-vapor flux could occur over long periods. Note, however, that this estimate of $F_{m}$ represents an extreme upper limit to possible steady-state moisture fluxes, not only because of the values assumed, but also because it is probably more realistic to assume that soil adsorption rather than free saturation controls temperature and vapor-pressure gradients in the soil. In such a case the above arguments still hold, with the adsorption curve replacing the saturation vapor-pressure curve. The derivative $(d e / d T)$, would be replaced by the corresponding derivative for the appropriate adsorption curve, which inevitably has a smaller value for given $T_{a}$ and $e_{a}$ than $(d e / d T)_{s}$.

The above arguments certainly do not rule out a local moisture source interpretation for the $W$ cloud features. They do perhaps make such an interpretation less plausible, and they also suggest that if these features do turn out to be local moisture-source areas, they are probably also thermal sources as well.

\section{Comments on Implications for Mariner 71}

The widespread thin hazes observed in M6 and M7 pictures raise the question of the extent to which subtle veiling and brightness effects of haze may be responsible for the variety of seasonal and secular variations in contrast and color observed over the long history of earthbased observations of Mars. The Mariner '71 $\mathrm{B}$ mission affords the opportunity for obtaining frequent pictures of the limb of the planet over a several month interval. Such pictures should provide much valuable information on the planet-wide distribution and time variations of thin hazes. Even pictures having a pixel resolution of about $6 \mathrm{~km}$, obtainable from $\mathrm{A}$-frame apoapsis photography, will be quite useful for determining the distribution of high-level thin hazes. Higher resolutions, of perhaps a few hundred meters, will be needed to observe lower level hazes and to derive information on haze structure. High-resolution coverage of regions observed to have limb haze at low resolution, together with low-to-medium- resolution color and polarization coverage of haze layers will be very helpful in limiting the range of possible particle types responsible for haze. Polarization should also prove useful in identifying haze against the background of the planet itself

The discrete bright features observed in the far-encounter phases of the Mariner ' 69 missions are an intriguing target for the $1971 \mathrm{~B}$ mission. It will be particularly important to determine, with the aid of nested resolution coverage to the highest resolution attainable, the nature of these features, particularly whether they are on the ground or in the atmosphere. Diurnal time coverage of these features should be obtained when they are active. The fact that most, if not all, of these features occur in a known limited region of Mars simplifies planning for this coverage, but the flexible operational mode planned for the B mission will be very useful, both because the bright activity is known to vary in time, and because similar features, or other types of discrete bright features, may be observed in other regions. Unfortunately, many bright cloud features will be at an inactive seasonal phase at the arrival time of the orbiters, so that it is likely that the most useful information will come from the later stages of an extended mission (Dean and Smith, unpublished data, 1970).

Acknowledgments. We are grateful to the many NASA and JPL personnel who made successful accomplishment of the Mariner 6 and 7 missions possible. Valuable assistance in the preparation of this paper was provided by S. A. Collins, G. E. Danielson, T. Rindfleisch, J. Dunne, and W. Stromberg of the Jet Propulsion Laboratory, J. E. Cutts of the California Institute of Technology, and R. Zurek of the University of Washington. Discussions with our colleagues B. C. Murray, M. E. Davies, R. P. Sharp, and A. Herriman have been most helpful. 
The participation of C. B. Leovy was supported in part under NASA grant 48-002-073."

\section{References}

Anderson, D. L., The evolution of terrestrial-type planets, Appl. Opt., 8, 1271-1278, 1969.

Dunne, J., W. Stromberg, R. M. Ruiz, S. A. Collins, and T. E. Thorpe, Maximum descriminability versions of the near-encounter frames, J. Geophys. Res., 76, this issue, 1971.

Gierasch, P., and R. M. Goody, A study of the thermal and dynamical structure of the Martian lower atmosphere, Planet. Space Sci., 16, 615646 and $1393-1397,1968$.

Leighton, R. B., N. H. Horowitz, B. C. Murray, R. P. Sharp, A. H. Herriman, A. T. Young, B. A. Smith, M. E. Davies, and C. B. Leovy, Mariner 6 and 7 pictures: Preliminary analysis, Science, $166,49-67,1969$.

Martin, L. J., and W. A. Baum, A study of cloud motions on Mars, Final Rep. Part B, Contract 951547, Jet Propul. Lab. Planet. Res. Center, Lowell Observ., Flagstaff, Ariz., 1969.

Neugebauer, G., G. Munch, S. C. Chase, Jr., H. Hatzenbeler, E. Miner, and D. Schofield,
Mariner 1969: Preliminary results of the infrared radiometer experiment, Science, 166, 98-99, 1969. Rasool, S. I., J. S. Hogan, R. W. Stewart, and L. H. Russell, Temperature distributions in the lower atmosphere of Mars from Mariner 6 and 7 radio occultation data, J. Atmos. Sci., 27, 841843, 1970.

Rindfleisch, T., J. Dunne, H. J. Frieden, W. Stromberg, and R. M. Ruiz, Digital processing of the Mariner 6 and 7 pictures, J. Geophys. Res., 76, this issue, 1971 .

Sharp, R. P., B. C. Murray, R. B. Leighton, L. A. Soderblom, and J. E. Cutts, The surface of Mars, 4, The south polar cap, J. Geophys. Res., 76, this issue, 1971 .

Young, A. T., High-resolution photometry of a thin planetary atmosphere, Icarus, 11, 1-23, 1969.

Young, A. T., and S. A. Collins, The photometric properties of the Mariner cameras and of selected regions on Mars, J. Geophys. Res., 76, this issue, 1971.

(Received August 10, 1970; revised September 17, 1970.) 